\title{
A Study on the Effectiveness of Conflict Management in the Private Retail Sector, in Copperbelt Province
}

\section{OPEN ACCESS}

Manuscript ID:

MGT-2020-08023330

Volume: 8

Issue: 2

Month: October

Year: 2020

P-ISSN: 2321-4643

E-ISSN: 2581-9402

Received: 04.07.2020

Accepted: 20.08 .2020

Published: 01.10.2020

Citation:

Velmurugan, T., et al. "A

Study on the Effectiveness

of Conflict Management in

the Private Retail Sector, in Copperbelt Province."

Shanlax International Journal of Management, vol. 8, no. 2, 2020, pp. 1-6.

DOI:

https://doi.org/10.34293/ management.v8i2.3330

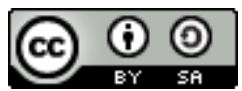

This work is licensed under a Creative Commons Attribution-ShareAlike 4.0 International License.

\section{T. Velmurugan}

Lecturer \& Research Scholar, Department of Social Work

DMI - St. Eugene University, Zambia

(D) https://orcid.org/0000-0002-3601-5867

\section{T. Marirajan}

Associate Professor \& Research Guide

School of Social Science \& Management, MOSA University, Zambia

\section{Gayathri}

Lecturer, Department of Social Work, DMI - St. Eugene University, Zambia

\section{Abstract}

Background: Conflict management is a process of limiting the negative aspects of conflict and increasing positive aspects of the conflict. It is for this purpose that this study is designed to examine the strategies involved in conflict management in the workplace, and in particular, the private retail sector in Copperbelt Area.

Methods: The study was done from the beginning of 2016. The methodology used for this study quantitative method using questionnaires, interviews, and observations, while secondary data generated from official documentations. The study considered a total of 50 respondents from the three retail industries in Copperbelt, respectively.

Results: Having studied the opinions of the various stakeholders as far as this research is concerned, it is stated that conflict management systems have proved to be otherwise effective, further resulting in directing employee energies towards the achievement of organizational goals and objectives. $74 \%$ of respondents accounted for positive responses recorded as being effective, whereas $26 \%$ recorded as a negative response.

Conclusion: The study recommended that Organizations should be enlightened about conflict management processes at the time of incorporation to clearly understand measures to be taken when the need arises.

Keywords: Conflict Management, Conflict Resolution, Employee Conflict and Positive Conflicts

\section{Introduction}

\section{Conflict Management}

Conflict is a dynamic process, just as conflict management is a process. Conflict does not always surface in gale proportions. An essential element of a conflict management process is the recognition that there are stages of the conflict, with appropriate interventions at different stages. The stages of conflict can range from robust argument within a single meeting to longstanding opposing, entrenched positions of organizational staff, administration, and the governing body. Depending upon the culture or needs of the organization and the type of conflict, an administrator or leader can use various communication skills and negotiation techniques to manage a conflict. 
Major changes and continued turbulence in the social, political, technological, and economic environments at a global level, but also locally in Zambia, are creating an uncertain and complex environment in which organizations have to operate. Fuelled predominantly by rapid advances in the information and communications technology sector, globalism has become both a cause and a consequence of sustained change, which, by all accounts, appears to be increasing in magnitude and pace.

The behavioral or contemporary view, also known as the human relations view, emerged in the late 1940s and held its way through the 1970s. It argues that conflict is natural and inevitable in all organizations and that it may have either a positive or a negative effect, depending on how the conflict is handled. Performance may increase with conflict, but only up to a certain level, and then decline if the conflict is allowed to increase further or is left unresolved.

These transformations are changing much in the world, including, it seems, the shape of organized violence and how governments and others try to set their limits. One indication of change is the noteworthy decrease in the frequency and death toll of international wars in the 1990s. Subnational ethnic and religious conflicts, however, have been so intense that the first post-Cold War decade was marked by enough deadly lower-intensity conflicts to make it the bloodiest since the advent of nuclear weapons. (Wallensteen and Sollenberg, 1996).

Conflicts inevitably arise between individuals in an organization, between organizational units, and between institutions. It is a part of our everyday life. Alarmingly, there are several studies that estimate that $30 \%$ to $40 \%$ of managers' daily activities are devoted to dealing with some form of conflict. Employees' inability to effectively deal with anger and conflict in the workplace can result in a tremendous loss of productivity, not to mention the emotional impact on all the participants. Conflict management also plays an important role in our personal lives. Conflict management prevents fall out between family members, friends, relatives, and makes life peaceful and stress-free. Blame games never help anyone; instead, it makes life miserable. No idea can ever be implemented if the individuals fight among themselves.
This is in line with Sisk and Williams'(1981) definition of conflict as the process which begins when one party perceives that one or more of its concerns have been or are about to be frustrated by another party. From various points of view, the definition of conflict connotes that a trace of competition cannot be ruled out. To some, conflict is synonymous with violence, but to the United Nations International Children's Emergency Fund (UNICEF, 1995), conflict is not necessarily synonymous with 'violence,' and that conflict occurs not only in situations of violence but conflicts inevitably occur between people over ideas, values, positions, and perspectives on a range of issues.

Blaine Donais (2006), in his book entitled Extract from Workplaces That Work: A Guide to Conflict Management in Union and Non-Union Work Environments, mentioned that anyone purporting to help a workplace manage conflict should take a careful look at the context in which that conflict exists. Every workplace has a culture. This culture is unique to that workplace. Without understanding this culture, it will be difficult to help the workplace make enduring changes to the way it manages conflict. Culture generally refers to a system of shared beliefs, values, and norms that shape behavior.

Thus the element of culture is perceived as religion, language, fashion, philosophy, and identify similarities among a certain group and differences with other groups. Workplace culture can be defined as the "way of life" for those in a particular workplace.

Hence this study enquired nature and source of conflict and the possible way to address organizational conflict using conflict resolution techniques.

\section{Objectives \& Methods \\ Major Objectives of the Study}

- To examine the conflict management system in the private sector, in particular, the retail industry.

- To establish what conflict management strategies have been put in place by authorities.

- To assess the extent/effectiveness at which the identified strategies have helped in running the company. 
- To study the working environment in regards to the measures taken concerning conflict management.

- To propose a recommendation for an effective and adequate conflict management system depending on the success levels or inadequacy of readily available strategies.

\section{Material and Methods}

In dealing with any real-life problem, it is often found that data at hand are inadequate, and hence, it becomes necessary to collect data that are appropriate. There are several ways to collect the necessary data at the researcher's disposal, which differ significantly in the context of money costs, time, and other resources. In this case, methods such as observation, which implies the collection of information by way of the investigator's observation, without interviewing the respondents. The knowledge gathered relates to what is happening at the moment and is not influenced by respondents' past actions or potential plans or attitudes. No doubt, this method is costly, and the knowledge given by this method is also very small. As such, this approach is inadequate for inquiries about large samples. Thus, personal interviews follow a rigid procedure and seek answers to a set of pre-conceived questions through personal interviews. This method of collecting data is usually carried out in a structured way where output depends upon the ability of the interviewer to a large extent.

The method used to collect data was made possible through first-hand information and secondary data published sources. Primary data collected was by the method of the direct personal interview as well as a questionnaire method. On the other hand, secondary data was collected from publications such as journals, books, and articles.

\section{Results \& Discussion \\ Results}

After carrying out the frequencies on the population, the results indicated a total of fifty respondents in which 8 belonged to Max Stores, 3 from Carsimbo Mini Mart, 2 Pep Stores, 3 Jet Stores, 4 Spar Zambia, 7 Pound Stretcher, 6 Betzalel, 6 Pick 'n' Pay, 6 Food Lovers Market, 2 Game Stores and 3 Melissa Supermarket. The nature of service of retail industry shows that $38 \%$ of clothing, $38 \%$ food and Beverage, and 24\% Supermarket. The respondent, according to their gender, were males as recorded at $56 \%$, whereas females recorded a $44 \%$ participation rate.

Among the 50 respondents, the age range varied from 18-45 years. Within this age group, $16 \%$ of them are $18-25$, and $64 \%$ of them are $26-35$ and remaining 36-45 age group are 20\%

The respondents, according to working hours, show that 46 percent working 1-8 hrs and the remaining 54 percent working 1-12 hrs-the percentage distributions by the occupation of the respondents. The highest number of respondents were skilled workers, accounting for $49 \%$ of the respondents, followed by semi-skilled workers, recording $28 \%$, professional workers indicating $15 \%$, and unskilled workers totaling $8 \%$ of the total number of respondents. All organizations seemingly recorded a $100 \%$ rate as is stimulated by stiff regulations highlighted in the organizational code of conduct.

Moreover, the Human Resources Department must ensure active employee representation in cases of grievance procedures. It is inevitable to state that conflict is bound to erupt in any social gathering. Hence the $100 \%$ recorded indicated the efforts put in; to achieve harmonious operations.

Represents the percentage distribution by clearly defined systems of conflict management in organizations. A clear percentage distribution ratio of $94 \%$ to $6 \%$ stipulated a positive response was; $94 \%$ indicated clearly defined systems as $6 \%$ of the population recorded otherwise. This may be a result of a lack of administrative training in particular fields. Employee participation in designing conflict management techniques shows that $16 \%$ of the total population illustrates employee participation in designing conflict management techniques, whereas $84 \%$ represents a total of respondents not in positions to suggest measures and techniques concerned with this research field. Represents a percentage distribution made by comparison of employee involvement in the decision making process with regards to the stated phenomena of management of conflict in various organizations of this research study. $28 \%$ of the total population recorded positive responses whereas $72 \%$ recorded otherwise. 
Among 50 respondents, according to the effectiveness of conflict management, conflict management systems have proved to be otherwise effective, further resulting in directing employee energies towards the achievement of organizational goals and objectives. $74 \%$ accounted for positive response recorded as being effective, whereas $26 \%$ recorded otherwise. The number of respondents recorded in comparison to the extent of effectiveness highlighted as "Highly effective," "Satisfactory," and "Unsatisfactory," respectively. Upon completion of frequency records, 31 respondents eluded to having highly effective results of conflict management, whereas 9 respondents eluded to having satisfactory results. Also, 10 respondents accounted for 20\% of the population with unsatisfactory remarks concerning the effectiveness of current systems.

Improved labor relations results in the improved workforce, and efficiency $74 \%$ accounting for improved workforce may be as a result of focused energies and redefined organizational goals $26 \%$ of non-improved efficiency may be attributed to the lack of defining clearly the purpose and goals of the existence of the given industry. Distribution of effectiveness of communication shows that $74 \%$ accounting for a population with highly effective communication patterns, $12 \%$ accounting for satisfactory communication patterns, and finally, $14 \%$ accounting for unsatisfactory/poor communication patterns.

In conclusion, this chapter was aimed at explicating the results and findings of the research by systematically grouping the respondents into categories and frequencies as well as percentages to calculate the average, means, and majorities.

\section{Discussion}

The highest number of respondents, as is concerned with this study, were skilled workers, accounting for $49 \%$ of the respondents, followed by semi-skilled workers, recording $28 \%$, professional workers indicating $15 \%$, and unskilled workers totaling $8 \%$ of the total number of respondents. A clear assumption can be assumed that most of the employees in these organizations are skilled workers representing $49 \%$ out of 50 respondents.
Hence the $100 \%$ respondents indicated the efforts put in; to achieve harmonious operations. A clear percentage distribution ratio of $94 \%$ to $6 \%$ stipulated a positive response was; $94 \%$ indicated clearly defined systems as $6 \%$ of the population recorded otherwise. This may be a result of a lack of administrative training in particular fields. However, it is clear to state that not all employees are allowed to decide on techniques of conflict management to be implemented in their respective organizations.

Completion of frequency records, 31 respondents eluded to having highly effective results of conflict management, whereas 9 respondents eluded to having satisfactory results. Also, ten respondents accounted for $20 \%$ of the population with unsatisfactory remarks concerning the effectiveness of current systems.

It is concluded that the prevailing $74 \%$ accounting for improved workforce may be as a result of focused energies and redefined organizational goals. $26 \%$ of non-improved efficiency may be attributed to the lack of defining clearly the purpose and goals of the existence of the given industry. 74\% accounting for a population with highly effective communication patterns, $12 \%$ accounting for satisfactory communication patterns, and finally, $14 \%$ accounting for unsatisfactory/poor communication patterns.

\section{Recommendations}

Organizations should make adequate room for participation both from employers and employees, fostering cooperation and integration of new and improved ideas on how best to maintain quality standards of workplace efficiency.

Employee health should be taken into account to ensure smooth operation and optimal efficiency. Align employment with stipulated working conditions that are favorable and realistic at all times.

To avoid rumors mongering or misplaced information, organizations should evolve a proper system of information dissemination to all.

Managers should learn to avoid delegating power to lower-ranking staff members.

Participatory rather than the autocratic style of management should be encouraged by organizations.

Conflict settlement should require sufficient dialogue and discussion to create a harmonious environment. 
Competition for dominance should not be the aim of the organizations' workers but rather work together in harmony and cooperation to accomplish a shared goal for the organizations' good.

Training workshops should be done for staff of organizations on conflict management procedures,

More research should be carried out on assessing the extent to which defined and identified strategies are of success not only in the private sector; moreover, research must cater to a broad spectrum of business entities. International organizations, governments, and students should participate more in this context to develop models that would improve the compliance of defined strategies.

Organizations should be enlightened about conflict management processes at the time of incorporation to clearly understand measures to be taken when the need arises.

\section{Conclusion}

Research has shown that significant numbers of people are involved with various forms of organizational conflict processes and procedures. However, there has been minimal research to indicate exactly the extent to which the strategies have been effective in operational undertakings, especially in the private sector.

In this view, this study was conducted to highlight missing factors, as identified above. The study used online literature as well as qualitative and quantitative approaches to determine outcomes. Questionnaires and in-depth interviews were used as tools for data collection.

The major findings of the study revealed that $100 \%$ of the organizations had in existence; clearly defined strategies of conflict management. Nonetheless, managerial positions must see to it that continuity and fairness are at play in determining workable solutions. Employees are generally at risk of being exposed to conflict, as it is an inevitable procedure in all working environments.

Good employee-employer relations result in highly effective communication, fostering improved workforce as well as full participation to facilitate quality in operations. As shown by the study, 74\% of the chosen population recorded having effective communication patterns as another $74 \%$ proved effective with regards to operational requirements and undertakings. However, the government must continue to work towards supporting, rewarding, and recognizing institutions that promote occupational freedom through credible conflict management procedures.

\section{References}

Abioro, Matthew Adekunle, et al. "Conflicts Management Strategies: A Tool for Industrial Harmony." Izvestiya Journal of Varna University of Economics, vol. 63, no. 1, 2019, pp. 19-34.

Abramson, Neil R. "Building and Maintaining Effective Buyer-Seller Relationships: A Comparative Study of American and Canadian Expectations." Journal of Promotion Management, vol. 12, no. 1, 2005, pp. 129-150.

Alexander, Mark. Transforming your Workplace; A Model for Implementing Change and Labour Management Cooperation, IRC Press, 1999.

Annual Report, United Nations International Children's Emergency Fund, 1995.

Ashe-Edmund, Sam. "Advantages \& Disadvantages of Conflict in Organizations." Chron, 2019.

Din, Siraj, et al. "An Investigation of Conflict Management in Public and Private Sector Universities." African Journal of Business Management, vol. 5, no. 16, 2011, pp. 6981-6990.

Donais, Blaine. Workplaces that Work: A Guide to Conflict Management in Union and NonUnion Work Environments, Canada Law Book, 2006.

Kasenge, Clement. "Conflict Management Strategies among Secondary School Leaders in Kitwe District in the Copperbelt Province in Zambia." International Journal of Research and Innovation in Social Science, vol. 4, no. 2, 2020, pp. 153-166.

Moberg, Philip J. "Linking Conflict Strategy to the Five-Factor Model: Theoretical and Empirical Foundations." International Journal of Conflict Management, vol. 12, no. 1, 2001, pp. 47-68.

Murerwa, Tabitha, and Florence Guantai. "Conflicts and Conflict Management in Modern 
International Journal of Management

Organisations - A Pre-Conflict Resolution Tonder, Chris Van, et al. "The Causes of Conflict Environment Approach." International in Public and Private Sector Organizations in Journal of Scientific and Research South Africa." Managing Global Transitions, Publications, vol. 9, no. 8, 2019, pp. 749-757. vol. 6, no. 4, 2008, pp. 373-401.

Ramani, Ken, and Liu Zhimin. "A Survey on Conflict Wang, Nannan, and Guobin Wu. "A Systematic Resolution Mechanisms in Public Secondary Approach to Effective Conflict Management Schools: A Case of Nairobi province, Kenya.” $\quad$ for Program.”Sage Open, vol. 10, no. 1, 2020.

Educational Research and Reviews, vol. 5, no. 5, 2010, pp. 242-256.

\section{Authour Details}

T. Velmurugan, Lecturer \& Research Scholar, Department of Social Work, DMI - St. Eugene University, Zambia,

EmailID: velusocialwork@gmail.com

Dr. T. Marirajan, Associate Professor \& Research Guide, School of Social Science \& Management, MOSA University, Zambia,Email ID: tmarirajan@gmail.com.

Mrs. V. Gayathri, Lecturer, Department of Social Work, DMI - St. Eugene University, Zambia,

Email ID: vgayathri2019@gmail.com. 